\title{
PRESERVATION AND PROMOTION OF INTANGIBLE CULTURAL HERITAGE - A PARTICIPATORY DESIGN APPROACH
}

\author{
Line Blom SALVESEN and Martina KEITSCH \\ Department of Design, Norwegian University of Science and Technology (NTNU)
}

\begin{abstract}
Current research literature on intangible cultural heritage ( $\mathrm{ICH}$ ), conservation, and development increasingly acknowledges that ICH has meaning for multiple stakeholders and is served best by integrating them into conservation processes. This article explores participatory design and its methods and tools for ICH purposes because they seem to provide promising approaches for keeping ICH vital in the traditional cultural locations and settings, as well as in the diasporas.

Following the introduction, the second part of the article explores the role of design when preserving and promoting intangible cultural heritage (ICH) in theory by reviewing the literature on ICH management, participatory design, and participatory preservation projects. The third part applies findings from part 2 in a participatory design project on ICH preservation in the diaspora community of Uyghurs in Norway. The conclusion in part 4 discusses learning experiences on combining design research and practice in a master's course. The goal of the project was to design a concept, that displays, disseminates, and connects Uyghur culture internally amongst the people in the diaspora as well as mediate Uyghur ICH to people in the Norwegian society. Findings of both the theoretical study and the project indicate that the sustainability of ICH preservation depends on that living heritage is kept alive. For this to happen, ICH must be allowed to transform according to the time and place of the culture bearers. This kind of transformation is especially significant for diaspora cultures.
\end{abstract}

Keywords: Participatory design, intangible cultural heritage, diaspora, preservation, cookbook

\section{INTRODUCTION}

The Uyghur culture is at risk of disappearing. Both the tangible and intangible cultural heritage of Uyghurs, who are today living in Xinjiang Autonomous Region is controlled and restricted by Chinese authorities. As a result, Uyghurs, whose culture is quite distinct from the majority Han Chinese culture, are at risk of losing their identity, cultural expressions, and religion. Uyghur inhabitants are under heavy surveillance, restricted from leaving China and having contact across the borders. Uyghur refugees have settled in many countries all over the world, and most of them are eager to do what they can to preserve their cultural heritage and protect their human rights while living in the diaspora.

\subsection{Methodological approach and background of the study}

The study presented in part 2 and 4 comprises a literature review and a practical project which are both part of a Master course at the Department of Design at the Norwegian University of Technology in Trondheim, Norway. The objectives of the course are to write a scientific article on a self-chosen topic to gain theoretical insights, to apply these insights in a project, which further explores the topic, and to present a design concept/solution. The literature review article provided the student, who is the first author, with a deeper understanding of the role of the designer in cultural heritage projects, while the project aimed to find a solution to preserve and promote the intangible cultural heritage of approximately 2500 Uyghurs living in Norway. The following part of this article is discussing participatory approaches concerning intangible cultural heritage preservation and promotion and explores how engaging the relevant communities can contribute to cultural revitalization, strengthening of identity, and social sustainable development. 


\section{INTANGIBLE CULTURAL HeRITAGE PRESERVATION}

Intangible cultural heritage (ICH) is defined as the immaterial expression of cultural heritage. It includes oral traditions, language, values, ways of living, social practices, performing arts like dance and music, knowledge, skills of handcraft and place-making, and so on. [1]

UNESCO's definition of cultural rights includes: "... the rights of individuals and communities to enjoy and make use of cultural heritage and cultural expressions, as well as the right to play an equal role in the identification, safeguarding, and transmission of their cultural heritage" (UNESCO, n.d.)

The declaration thereby points out that the need for ICH safeguarding is connected to human rights and serves as a reference point for the elaboration of policies in favour of cultural diversity [2]. A major issue concerning the practice of safeguarding heritage is however that policymakers determine what is worth safeguarding and what can be neglected, or even looked upon as a threat to society. This is problematic in terms of decision-making and the UNESCO cultural heritage programme has been criticized for it by various authors, who argue that state institutions can exploit policies in their favour [3], [4], [5] using heritage interventions as political instruments. Though required to consult the heritage bearers, the lack of communication with the relevant groups often goes unnoticed.

Another challenge pointed out by Mountcastle [5], is the contradiction between the living character of ICH that transforms through dynamic processes and continuous decision-making and the act of identifying and listing the ICH as something consistent. ICH develops and changes over time, responding to events, conditions, and development of societies. For that reason, traditions and practices in diaspora communities are never the same as in the homelands, but are nevertheless "authentic", as the diaspora community has developed their own ICH, where heritage is interpreted and re-invented to respond to the new time and setting [6]. Due to the living characteristics of ICH, participatory approaches must address the heritage bearers directly, both when dealing with ICH in its original place or diaspora [3], [7]. Although criteria of participation are sometimes applied loosely several newer ICH projects, which were analysed by the first author of this article, are aiming at culture bearers' participation.

\subsection{The role of Participatory Design in preserving $\mathrm{ICH}$}

Participatory approaches in heritage management are often used to address the stakeholders' relationships to the heritage that is dealt with. This can reveal the intangible traditions connected to a place, objects, or monuments defined as tangible cultural heritage. It opens discussion and can help to record knowledge. Participatory design (PD) in particular, uses participatory approaches to reach some sort of tangible or intangible outcome, whether it is a new service, experience, system, or product [8]. PD also comes in varying degrees of participation, and the level of empowerment experienced by participants relates to the level of participation. Davidson et. al. illustrates this with the "Ladder of community participation" (Figure 1), which shows that user participation in PD can range from "manipulation" of users as the workforce to "collaboration", or most preferably "empowerment", which leaves the user with the most control of decision-making and execution of the project [9]. These authors also suggest that a participatory approach, in particular, is useful to realize projects (like surroundings, architecture, services, events, and exhibitions).

In the light of Davidson's Ladder [9] of community participation, real grass-root heritage projects are the most empowering, while simple actions as informing and consulting heritage bearers before actions deprive them of their autonomous ICH development and is, therefore, a violation of human rights.

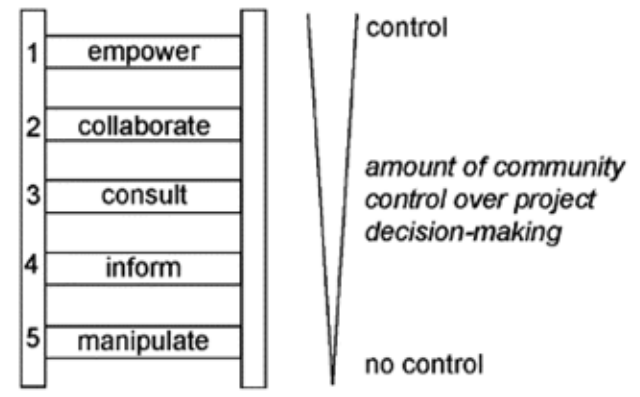

Figure 1. Davidson's Ladder for Community Participation 


\subsection{The analysis of case studies from literature}

To relate Davidson's ladder to real-life participatory design projects, the first author of this article analysed five case studies from the literature concerning their participatory content as displayed in Figure 2. One case was from Egypt [10], two from Finland [11] [12], one from Norway [13], and one from China [14].

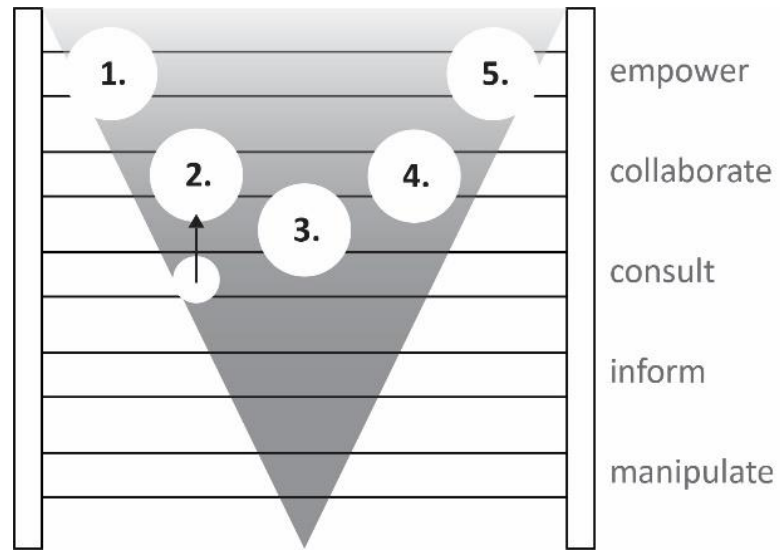

\section{Digital documentation of Egyptian Bedouins' ICH}

2. Adopt a monument

3. Reconstructing Guchengping village

4. Museums promoting the ICH of diasporas

5. Grassroot initiatives: The Norwegian Coastal Federation and Kaustinen music festival

\section{Figure 2. Participatory projects located in Davidson's Ladder (Figure designed by Author 1)}

The role of a participatory designer in participatory projects is both facilitating the participants to engage in the research and creation process, and to use the designers' skill of envisioning and visualizing concepts and ideas. Conclusively, the theory investigation resulted in summarizing three principles for participatory ICH projects:

1) to benefit the community by addressing their real needs and wants,

2) to promote motivation, ownership and authenticity by facilitating self-expression and decision-making by participants and

3 ) to create a shared identity between designers and participants [10 The role of a participatory designer in participatory projects is both facilitating the participants to engage in the research and creation process and to use the designers' skill of envisioning and visualizing concepts and ideas. Conclusively, the theory investigation resulted in summarizing three principles for participatory ICH projects:

1) to benefit the community by addressing their real needs and wants,

2) to promote motivation, ownership, and authenticity by facilitating self-expression and decisionmaking by participants and

3) to create a shared identity between designers and participants [10].

Findings from theory contributed to the decision to conduct the project and concept development as a participatory design approach, trying to include the users as much as possible in the process of creating. Participatory tools applied in the project were interviews to lead the project direction, a focus group to include users in decision making and further developments of the concept, and an iterative feedbackrefinement process to ensure that the end product is finished in terms with the users. The project methodology and process plan were built upon principles of user-centred design as well as participatory approaches.

\section{RESULTS}

The following section presents results in form of solutions for preserving and promoting Uyghur intangible cultural heritage within a participatory design concept. Based on the findings from desktop studies, stakeholder information and -interviews, and ideation concepts were discussed with a focus on the most relevant cultural aspects for the Uyghur stakeholder group: The concepts were: culinary culture, social life, literature, language, and music/dance. Figure 3 shows the 5 concepts that were considered for further development. 

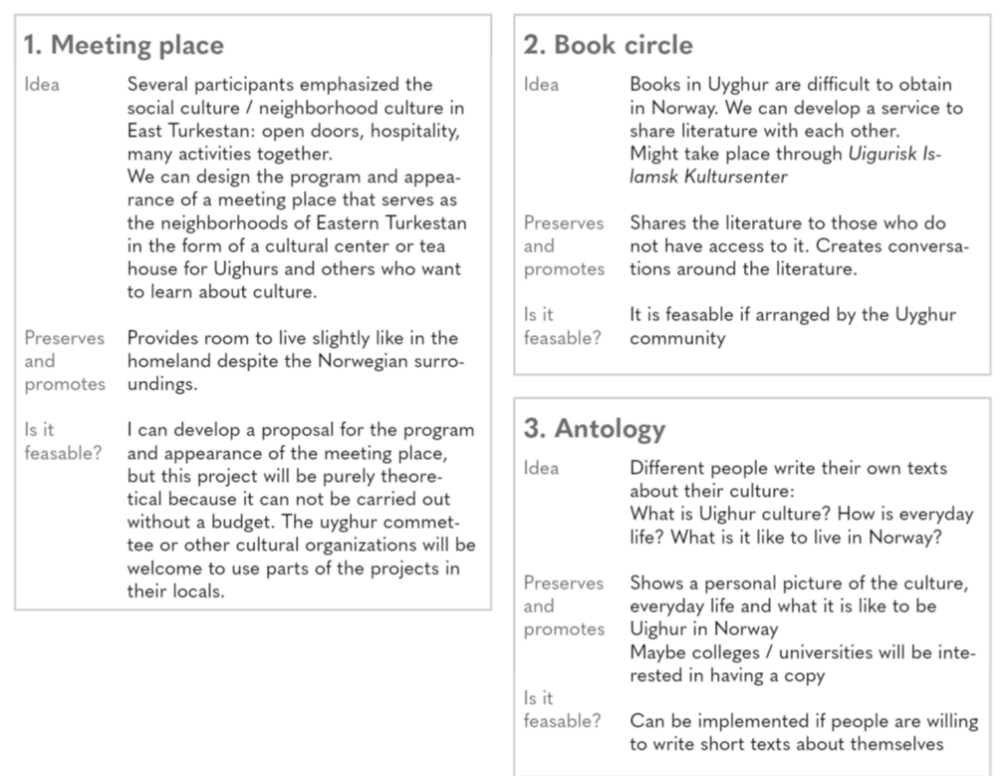

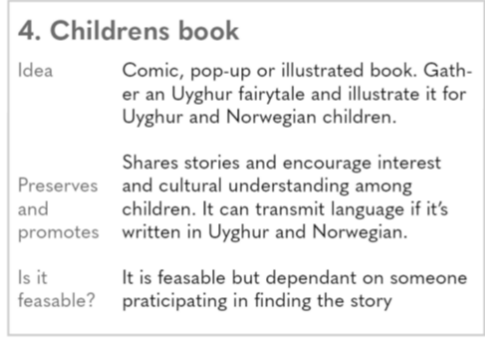

5. Cookbook

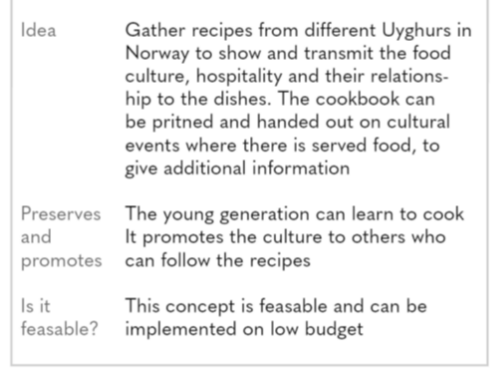

Figure 3. Concepts from Ideation phase

The concepts were evaluated regarding their cultural importance, but also relating to their realizability and preservation over time. The cookbook (5) was a good and easy option because food is something that concerns us all and Uyghurs are very proud of their cuisine. Also, a cookbook does not exclude any users from participation and eating is an important part of everyday life. A meeting place (1) also seemed like a good option, as it could embrace many aspects of the culture and especially the social life. It could have elements for each interest to appeal to many different people. However, facilitating the physical design of such a place can be challenging. The children's book (4) addresses the parents' wish to transmit knowledge about language, culture, and history to the younger ones. It could also see Norwegian kids as a target group to heighten understanding about cultural diversity. However, the target group for this concept is somewhat more limited and might contradict children's motives as not everyone is yet maturely motivated to learn about the language and cultural background of their parents.

The anthology (3) is more of a documentation form and might be less useful for everyday life safekeeping of the intangible heritage. There is also a high threshold to contribute with such personal written text and would not appeal to everyone. The book circle (2) is also for those who are especially interested and excludes those who are not as excited about reading.

To be able to appeal to more target users, both Uyghur and others, and to address cultural "living" heritage in a design solution and not only documentation, the concepts of cookbook and meeting place were chosen and presented to the focus group. All participants thought that food is an important part of the Uyghur culture and that food is a good channel to represent it. The participants thought that the cookbook was a good idea, but they were concerned about the fact that Uyghur cooking requires a lot of skills, and the cooking process is not easily described with text only. The participants were however positive about sharing their recipes in an online version. They also liked the meeting place concept and said they would probably go there themselves, although they were not so sure about what should be in such a place. After discussing the two concepts the cookbook was chosen both because it is more likely to be implemented and to find participants, and because food concerns everyone, and as one participant pointed out: "Our life and culture really cannot go on without food."

\subsection{Discussion of selected solution}

The selected solution that has been designed consists of a service that includes both a physical and digital format, to address all issues discovered in interviews and the focus group. The storyboard in Figure 4 explains the two main components of the service, a printed recipe booklet and a webpage, how they work together, and how it relates to the current practice of cultural events, "food-exhibitions" and Uyghur holidays like Nowruz and Eid. The printed recipe booklet is an addition to the database generated through the webpage. It cannot hold the videos, but it has an important function by having a presence in real-world cultural events that are currently arranged by different Uyghur societies in Norway. Since Uyghur food is often complicated, the booklet should direct the user to the webpage with the current 
recipe if it has a video. In addition to the recipes, it should also give background information about the food, like where it originates, who submitted the recipe, what is the author's relationship to the recipe, etc. Since the recipe owners are the ones submitting this information, they can define and express themselves the culture connected to the food.

The service needs an administrator, which could be the culture branch of the Norwegian Uyghur Committee who also arranges events. The administrator should handle the webpage and recipes submitted and prepare and print the booklet for events.
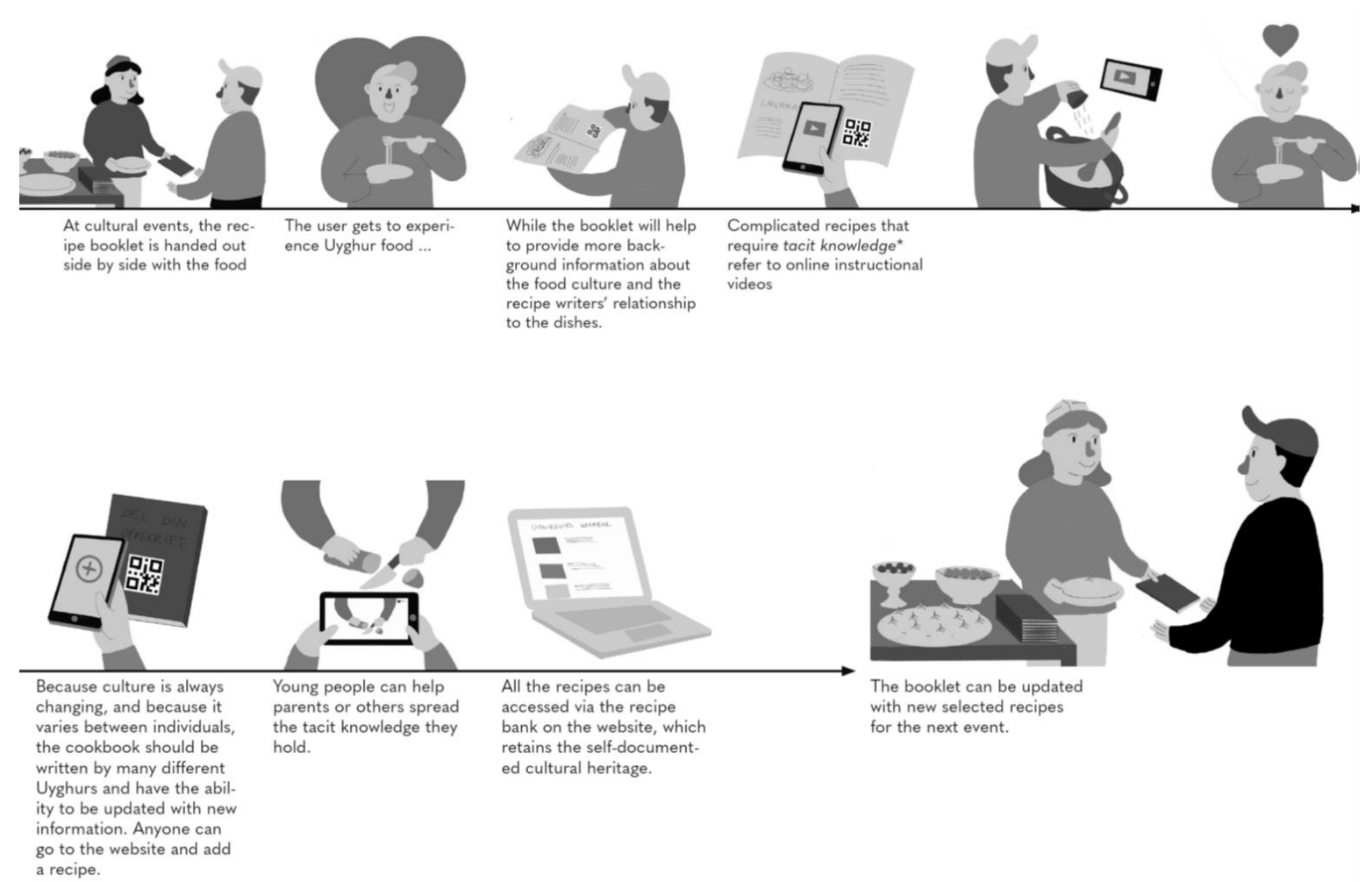

Figure 4. Cookbook Story Board

Due to the COVID-19 outbreak, Norway was in a lock-down from March 2020 till the project deadline and it was very difficult to get a response from the focus group on the final concept, so the feedback step before finishing and delivering the project was not done. The first author got feedback from a Uyghur friend, who was very positive about the concept and wanted to start submitting the recipes of her parents right away if it was realized. The proposed solution is therefore a prototype of iteration 1 . It needs to be user-tested and get feedback from Uyghur users. If further development will be done, important points to validate through the participants would be whether it represents their culture in their terms, whether they would use this system, if it is understandable and user-friendly.

\section{CONCLUSIONS}

By combining design theory and -practice in the project, the first author experienced the importance of participatory approaches in design problems concerning society and culture. The main challenge was to connect with the user group and to establish trust and mutual understanding in a limited time frame, especially because the users are outside of the author's social and cultural periphery. However, the project exemplified the theory that user engagement is crucial in cultural matters and that the role of the designer is among others to try to understand and facilitate the needs and values of people affected by the project. Intangible cultural heritage can be revitalized by new design solutions. The value of participatory approaches to the wider design and heritage community is increased stakeholder collaboration on a local and regional level and ICH activities that keep living heritage dynamic through direct user involvement. 


\section{REFERENCES}

[1] UNESCO. The Right to Culture. Available: http://www.unesco.org/culture/culture-sectorknowledge-management-tools/10_Info\%20Sheet_Right\%20to\%20Culture.pdf [Accessed on 2020, 13 December] (n.d.).

[2] UNESCO. Universal Declaration on Cultural Diversity. Available: http://portal.unesco.org/en/ev.php-URL_ID=13179\&URL_DO=DO_TOPIC\&URL_SECTION=201.html [Accessed on 2020, 13 December] (2001) 2 November.

[3] Aykan B. (2013). How Participatory is Participatory Heritage Management? The Politics of Safeguarding the Alevi Semah Ritual as Intangible Heritage. Int J Cult Prop, 20(4), 381-405.

[4] Blake J. (2019). Engaging "Communities, Groups and Individuals" in the International Mechanisms of the 2003 Intangible Heritage Convention. Int J Cult Prop, 26(2), 113-137. doi:10.1017/S0940739119000134

[5] Mountcastle A. (2010). Safeguarding Intangible Cultural Heritage and the Inevitability of Loss: A Tibetan Example. Studia ethnologica Croatica (22), 339-359.

[6] Affifudin A. H. (2017). Performing silat in Malaysian diasporic communities in Australia: a cultural heritage analysis of identities, performance, and self. (PhD). University of Queensland, Queensland.

[7] Naguib S.-A. (2013). Museums, Diasporas, and the Sustainability of Intangible Cultural Heritage. Sustainability (Basel, Switzerland), 5(5), 2178-2190. doi:10.3390/su5052178

[8] Lupo E. (2007). Intangible Cultural Heritage Valorisation: A New Field for Design Research and Practice. Paper presented at the International Association of Societies of Design Research, Hong Kong. Available: https://www.sd.polyu.edu.hk/iasdr/proceeding/papers/Intangible\%20heritage\%20valorisation_\%20a\%20new\%20field\%20for\%20design\%20research\%20and\%20practice.pdf. [Accessed on 2021, $02 \mathrm{March}$ ]

[9] Davidson C. H., Johnson C., Lizarralde G., Dikmen N. and Sliwinski A. (2007). Truths and myths about community participation in post-disaster housing projects. Habitat international, 31(1), 100-115. doi:10.1016/j.habitatint.2006.08.003

[10] Giglitto D., Lazem S., and Preston A. (2019). A Participatory Approach for Digital Documentation of Egyptian Bedouins Intangible Cultural Heritage. 31-49.

[11] Hakamäki M. (2017). Kaustinen - Valuing Local Culture. In A.-M. Halme, T. Mustonen, J.-P. Taavitsainen, S. Thomas, \& A. Weij (Eds.), Heritage is Ours (pp. 108-113). Helsinki: Forssa Press.

[12] Soininen T.-L. (2017). Adopt a Monument - Conserving the cultural environment for the people, with the people. In A.-M. Halme, T. Mustonen, J.-P. Taavitsainen, S. Thomas, \& A. Weij (Eds.), Heritage is Ours (pp. 56-61). Helsinki: Forssa Print.

[13] Schultz E. (2017). The Norwegian Coastal Federation, a successful "bottom-up" approach. In A.M. Halme, T. Mustonen, J.-P. Taavitsainen, S. Thomas, \& A. Weij (Eds.), Heritage is Ours (pp. 48-51). Helsinki: Forssa Print.

[14] Wu H. and Hou C. (2019). Utilizing co-design approach to identify various stakeholders' roles in the protection of intangible place-making heritage. Disaster prevention and management, 29(1), 22-35. doi:10.1108/dpm-09-2018-0291 